\title{
Enhanced dielectric and piezoelectric properties in multi-ferroic ceramics $\left[\mathrm{Ba}\left(\mathrm{Nd}_{0.1} \mathrm{Ti}_{0.8} \mathrm{Nb}_{0.1}\right) \mathrm{O}_{3}\right]_{(1-x)}\left[\mathrm{Na}_{0.5} \mathrm{Bi}_{0.5} \mathrm{TiO}_{3}\right]_{x}$
}

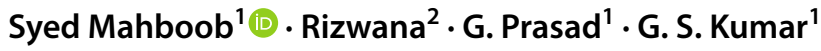

Received: 13 November 2019 / Accepted: 18 March 2020 / Published online: 31 March 2020

(c) Springer Nature Switzerland AG 2020

\begin{abstract}
The effect of NBT content on the dielectric and piezoelectric properties in multi-ferroic ceramics $\left[\mathrm{Ba}\left(\mathrm{Nd}_{0.1} \mathrm{Ti}_{0.8} \mathrm{Nb}_{0.1}\right)\right.$ $\left.\mathrm{O}_{3}\right]_{(1-x)}\left[\mathrm{Na}_{0.5} \mathrm{Bi}_{0.5} \mathrm{TiO}_{3}\right]_{x}$ has been studied. Ceramic compositions with $x=0.00,0.25$ and 0.65 were prepared through conventional solid state sintering route. Ceramic composition with high NBT content $(x=0.65)$ has shown twice the value of diffusiveness of phase transition when compared to without it. The electromechanical coupling conversion of 54-69\% was observed at room temperature. These ceramic samples also studied at higher temperature (673-898 K) exhibited greater than $90 \%$ electromechanical coupling conversion. These materials also studied at higher temperatures (673$898 \mathrm{~K}$ ) showed piezoelectric charge constant of the order of $\mathrm{nm} \mathrm{V}^{-1}$ when compared to at RT which in turn has the value of the order of $\mathrm{pm} \mathrm{V}^{-1}$. Enhanced piezoelectric charge constant at elevated temperatures and with the increase in NBT content is attributed to the field-induced strains happening due to the presence of polarized oxygen vacancies. The results indicate that the present ceramics are best suited for high-temperature transducer application.
\end{abstract}

Keywords Multi-ferroic · Dielectric · Piezoelectric · Electromechanical coupling

\section{Introduction}

Research has been carried out over the many decades to modify barium titanate and sodium bismuth titanate ceramics with suitable ions doping at lattice sites [1-12]. Solid solution of the above these compounds has also studied to enhance the various properties including the electrical, electromechanical and piezoelectric properties. Some researchers have been successful in enhancing the properties as stated above [13-22]. Swain et al. [23] studied the solid solution of $(1-x) \mathrm{Na}_{0.5} \mathrm{Bi}_{0.5} \mathrm{TiO}_{3}-(x) \mathrm{BaTiO}_{3}$ with $x=0.05$, $0.06,0.07$ and 0.08 in bulk ceramic form, and these showed interesting ferroelectric and piezoelectric properties. They reported the piezoelectric charge constant to be approximately $105 \mathrm{pC} / \mathrm{N}$ and electromechanical coupling factor $\left(K_{\mathrm{p}}\right)$ to be $21.17 \%$ for $x=0.07$ ceramic composition. Cernea et al. [24] reported piezoelectric charge constant to be 77
$\mathrm{pC} / \mathrm{N}$ for $5 \mathrm{~mol} \%$ of $\mathrm{BaTiO}_{3}$ in $\mathrm{Na}_{0.5} \mathrm{Bi}_{0.5} \mathrm{TiO}_{3}$ ceramic synthesized by sol-gel route. Similarly, Kang et al. [25] studied the $(1-x) \mathrm{Bi}_{0.5}\left(\mathrm{Na}_{0.78} \mathrm{~K}_{0.22}\right)_{0.5} \mathrm{TiO}_{3}-(x) \mathrm{BaTiO}_{3}$ lead-free piezoelectric ceramics prepared through sol-gel route. They observed piezoelectric charge constant of $167 \mathrm{pC} / \mathrm{N}$ and electromechanical coupling conversion efficiency of $45 \%$ for $x=0.06$. The results on the piezoelectric and electromechanical coupling conversion properties for the ceramics made from the solid solution of barium titanate and sodium bismuth titanate are interestingly high and can be further improved by rare earth doping $A$ and $B$ sites. This prompted the author to investigate the solid solution based on barium titanate and sodium bismuth titanate which exhibits good piezoelectric and electromechanical properties. In our earlier studies on barium titanate-based ceramics, i.e., $\left.\mathrm{Ba}\left(\mathrm{Nd}_{x} \mathrm{Ti}_{1-2 x} \mathrm{Nb}_{x}\right) \mathrm{O}_{3}\right]$, good dielectric relaxor behavior was observed for higher concentration of $x$ exhibiting higher value of electromechanical coupling

$\checkmark$ Syed Mahboob, mahboob1978@yahoo.com | ${ }^{1}$ Materials Research Laboratory, Department of Physics, Osmania University, Hyderabad, Telangana 500007, India. ${ }^{2}$ Institute of Aeronautical Engineering, Dundigal, Hyderabad, Telangana 500043, India. 
conversion in the range 0.49 to 0.67 depending up on $x$ value $[26,27]$. In order to further enhance the dielectric and piezoelectric properties, a binary system $\left[\mathrm{Ba}\left(\mathrm{Nd}_{0.1} \mathrm{Ti}_{0.8} \mathrm{Nb}_{0.1}\right)\right.$ $\left.\mathrm{O}_{3}\right]_{(1-x)}\left[\mathrm{Na}_{0.5} \mathrm{Bi}_{0.5} \mathrm{TiO}_{3}\right]_{x}$ with $x=0.00,0.25$ and 0.65 was chosen for present investigation. Dielectric, DC conductivity and electromechanical coupling studies were carried out on the above ceramic samples and were successful in enhancing the dielectric and piezoelectric properties with NBT content especially the piezoelectric charge constant. The results on the above studies are presented in the present paper and have discussed with suitable explanation.

\section{Experiment}

High-grade carbonates $\left(\mathrm{BaCO}_{3}, 99.9 \%\right.$, Merck), $\left(\mathrm{Na}_{2} \mathrm{CO}_{3}\right.$, 99.9\%, Merck) and oxides $\left(\mathrm{Nd}_{2} \mathrm{O}_{3}, 99.9 \%\right.$, Rare Earth India Ltd), $\left(\mathrm{Nb}_{2} \mathrm{O}_{5}, 99+\%\right.$, Nuclear Fuel Complex, India), $\left(\mathrm{TiO}_{2}\right.$, 99.99\%, Sigma-Aldrich), $\left(\mathrm{Bi}_{2} \mathrm{O}_{3}, 99.9 \%\right.$, Sigma-Aldrich) were used to prepare the present ceramic compositions. Weighed and thoroughly mixed stoichiometric mixture of oxides and carbonates was taken to prepare the ceramic compositions of $\left[\mathrm{Ba}\left(\mathrm{Nd}_{0.1} \mathrm{Ti}_{0.8} \mathrm{Nb}_{0.1}\right) \mathrm{O}_{3}\right]_{(1-x)}\left[\mathrm{Na}_{0.5} \mathrm{Bi}_{0.5} \mathrm{TiO}_{3}\right]_{x}$ (abbreviated as BNNT $_{(1-x)} \mathrm{NBT}_{x}$ ) with $x=0.00,0.25$ and 0.65 . The powder was calcined at $900^{\circ} \mathrm{C}$ for $3 \mathrm{~h}$ in the conventional high-temperature furnace. Compacted ceramic disks were final sintered at $1175^{\circ} \mathrm{C}$ for $2 \mathrm{~h}$ in conventional furnace. In the present study, the dielectric, capacitance resonance and anti-resonance data were obtained using HP4192A impedance analyzer. DC conductivity data were obtained using programmable Keithley 617 electrometer. The modulus resonance and anti-resonance data were obtained from the impedance measurements carried out using AUTOLAB PGSTAT30 lowfrequency impedance analyzer.

\section{Results and discussion}

Figure 1 a shows the dielectric constant as a function of temperature from 80 to $800 \mathrm{~K}$ at constant $10 \mathrm{kHz}$ frequency. It can be seen from these plots that the ceramic materials showed broad diffused phase transition. This is due to the $A$ and $B$ sites cationic disorder in the $\left[\mathrm{Ba}\left(\mathrm{Nd}_{0.1} \mathrm{Ti}_{0.8} \mathrm{Nb}_{0.1}\right)\right.$ $\left.\mathrm{O}_{3}\right]_{(1-x)}\left[\mathrm{Na}_{0.5} \mathrm{Bi}_{0.5} \mathrm{TiO}_{3}\right]_{x}$ with $x=0.00,0.25$ and 0.65 ceramics. The dielectric constant at RT is 730,590 and 1701 for $x=0$, 0.25 and 0.65 compositions, respectively. The higher value of room-temperature dielectric constant and at around $T_{\max }$ was observed for the ceramic composition $x=0.65$. This is due to
Fig. 1 a Dielectric constant versus temperature plots, $\mathbf{b}$ $\log \left(\left(1 / \varepsilon^{\prime}\right)-\left(1 / \varepsilon_{\max }^{\prime}\right)\right)$ versus $\log \left(T-T_{\max }\right), c$ degree of relaxor behavior $(\gamma)$ versus composition and $\mathbf{d}$ degree of diffusiveness of phase transition $(\delta)$ versus composition at $10 \mathrm{KHz}$
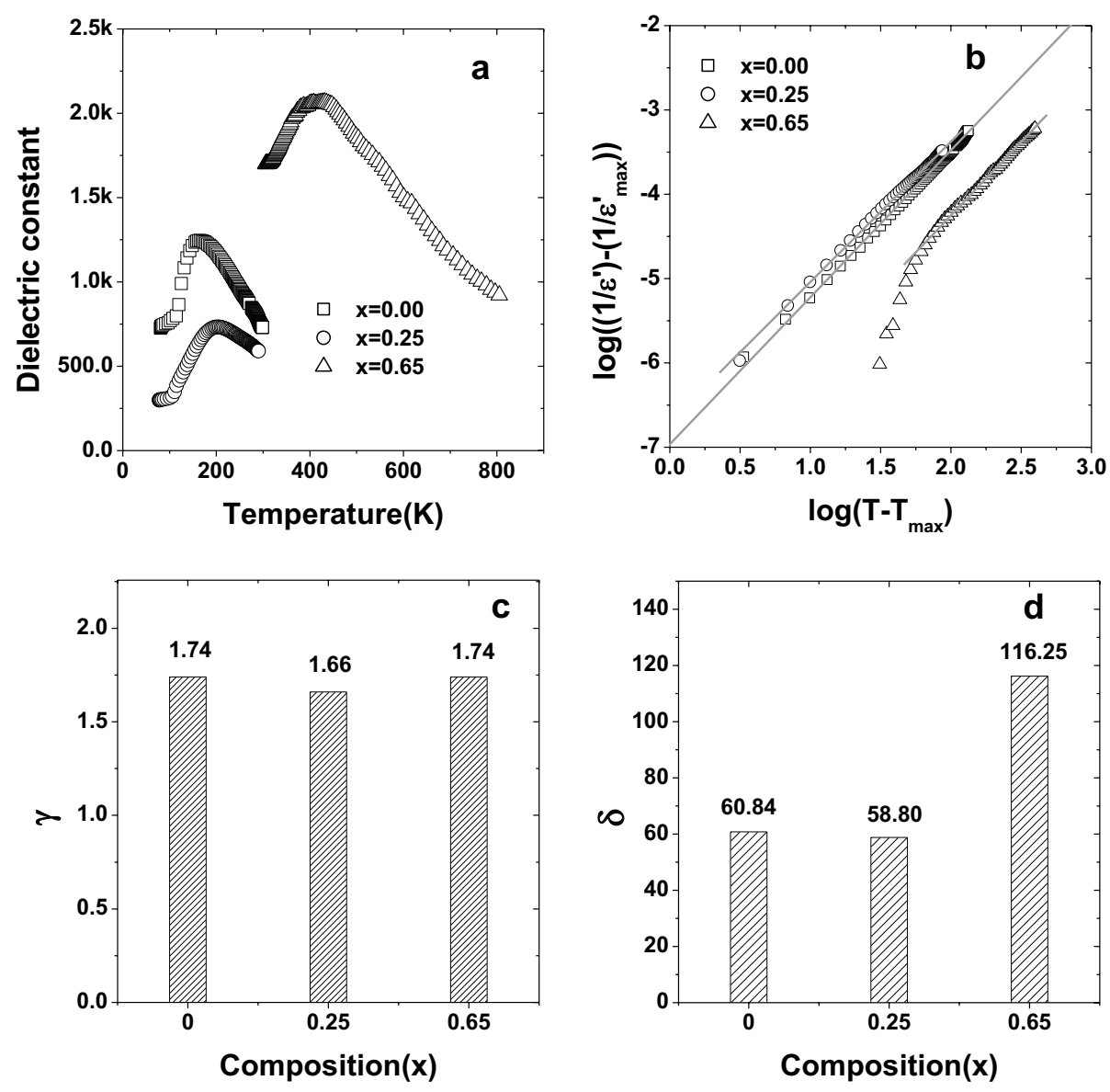
the more polarization in the crystal structure for $x=0.65$ which has rhombohedral symmetry when compared to other compositions which in turn has cubic symmetry at RT (Table 1). The higher value of dielectric constant for $x=0.65$ composition and also the dielectric transition temperature when compared to other compositions may also be due to steric effect arising due to substitution of more smaller ionic radii cations like $\mathrm{Na}^{+}$and $\mathrm{Bi}^{+3}$ at $\mathrm{Ba}^{+2}$ position [28]. Figure $1 \mathrm{~b}$ shows the inverse of dielectric constant as a function of $\log \left(T-T_{\text {max }}\right)$ at $10 \mathrm{kHz}$ frequency following Curie-Weiss square law. Linear fitting is done to obtain the degree of diffusiveness of transition $(\delta)$ and degree of relaxor behavior $(\gamma)$ from the intercept and slope of the linear fitting, respectively. It can be seen from Fig. 1c, $d$ that the degree of relaxor behavior does not change much with $x$ value, i.e., with the increase in NBT content. But the degree of diffusiveness of phase transition is almost the double for $x=0.65$ composition when compared to ceramic composition with $x=0.00$. This is due to more cationic disorder at A site which leads to broader distribution of transition temperatures.

Figure 2a shows the DC conductivity as a function of $1000 / T(K)$. The room-temperature resistivity is in the order of Giga $\Omega$-cm with slight variation with composition. From

Table 1 Parameters obtained from dielectric and DC conductivity data

\begin{tabular}{llll}
\hline $\begin{array}{l}\text { Dielectric and DC con- } \\
\text { ductivity parameters }\end{array}$ & \multicolumn{2}{l}{ Composition } \\
\cline { 2 - 4 } & $x=0.00$ & $x=0.25$ & $x=0.65$ \\
\hline Crystal structure & Cubic & Cubic & Rhombohedral \\
$a(\AA)$ & 4.042 & 3.999 & 3.958 \\
$a\left(^{\circ}\right)$ & - & - & 90.12 \\
$\varepsilon_{\mathrm{RT}}^{\prime}$ at $10 \mathrm{KHz}$ & 730 & 590 & 1701 \\
$T_{\max }(\mathrm{K})$ at $10 \mathrm{KHz}$ & 165 & 203 & 408 \\
$\gamma$ at $10 \mathrm{KHz}$ & 1.74 & 1.66 & 1.74 \\
$\delta(\mathrm{K})$ at $10 \mathrm{KHz}$ & 60.84 & 58.80 & 116.25 \\
$E_{\text {act }}(\mathrm{eV})$ & 0.97 & 0.80 & 1.34 \\
$(445-505 \mathrm{~K})$ & & & \\
\hline
\end{tabular}

room temperature to $1000 / T=2.5$, the ceramic materials showed slight PTCR effect, and at higher temperatures, these materials showed NTCR behavior. Linear fitting to conductivity data was done in the temperature range $445-505 \mathrm{~K}$ to obtain the activation energy for conductivity which is summarized in Table 1 and Fig. 2b. The activation energy for conductivity is $0.97 \mathrm{eV}, 0.80 \mathrm{eV}$ and $1.34 \mathrm{eV}$ for ceramic compositions $x=0.00,0.25$ and 0.65 , respectively. The higher value of activation energy greater than $1 \mathrm{eV}$ for $x=0.65$ indicates that the conductivity is due to oxygen vacancy-related phenomenon [29].

Figure 3a shows the capacitance resonance and antiresonance data at room temperature. It can be seen from figure that resonance and anti-resonance frequency increased with the increase in composition. From the equations on standard on piezoelectricity $[22,30]$, the thickness mode of electromechanical coupling factor and piezoelectric charge constant $\left(d_{33}\right)$ (Eq. 1$)$ was estimated and is depicted in Fig. 3b, $d$ and Table 2. Here in Eq. (1), $\rho$ is the density of the ceramic sample in $\mathrm{kg} / \mathrm{m}^{3}, C_{\mathrm{T}}$ is the capacitance in farads at $1 \mathrm{kHz}, d$ is the diameter of the ceramic disk in meters, $\mathrm{h}$ is the thickness of the ceramic sample in meters, fr is the resonance frequency in $\mathrm{Hz}$ and $\mathrm{fa}$ is the anti-resonance frequency in $\mathrm{Hz}$. It is observed that the electromechanical coupling conversion for these materials is in the range $54-69 \%$. The piezoelectric charge constant for $x=0.00,0.25$ and 0.65 is $29.88 \mathrm{pm} \mathrm{V}^{-1}, 31.35 \mathrm{pm} \mathrm{V}^{-1}$ and $33.35 \mathrm{pm} \mathrm{V}^{-1}$, respectively. The higher value of piezoelectric charge constant for $x=0.65$ is due to the field-induced strains happening due to the presence of polarized oxygen vacancies present in ceramic material at crystal lattice, at interstitial positions and across the grain boundaries. The presence of oxygen vacancies in ceramic composition $x=0.65$ can be known from the observation of activation energy for conductivity of $1.34 \mathrm{eV}$. In the present ceramic material, oxygen vacancies are formed due to multivalent cations occupying at lattice sites and also due to oxygen loss occurring due to sintering at higher temperatures. This
Fig. 2 a $\log \left(\sigma_{\mathrm{dc}}\right)$ versus $1000 / T$ and $\mathbf{b}$ activation energy $\left(E_{\text {act }}\right)$ versus composition in the temperature region $(445-505 \mathrm{~K})$
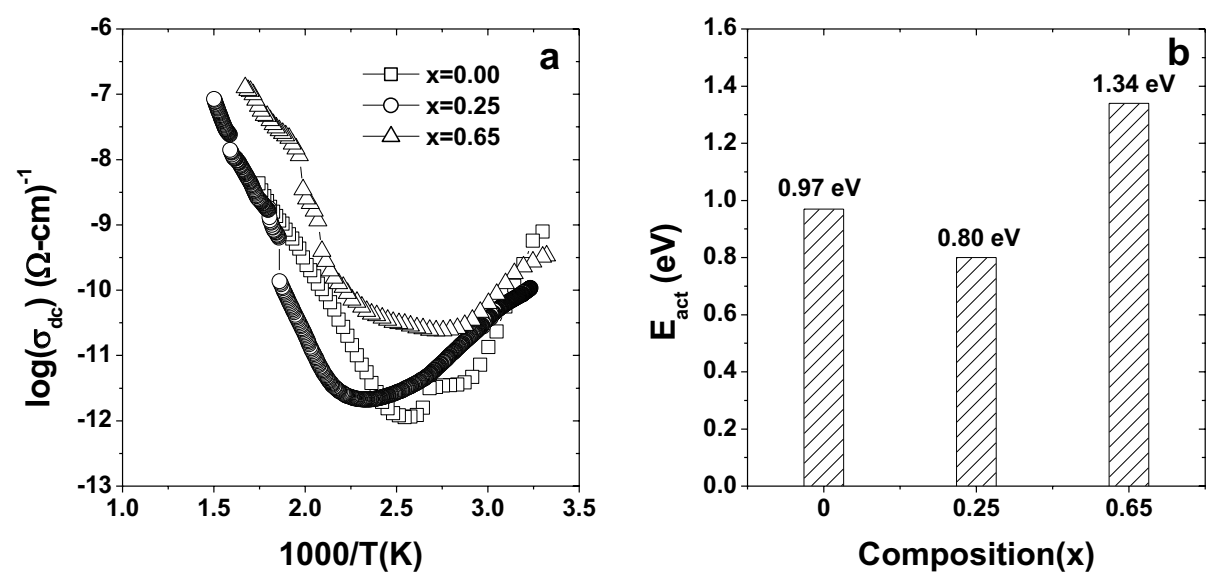

SN Applied Sciences A SPRINGER NATURE journal 
Fig. 3 a Capacitance versus frequency, b electromecomposition and c piezoelectric charge constant versus composition chanical coupling factor versus
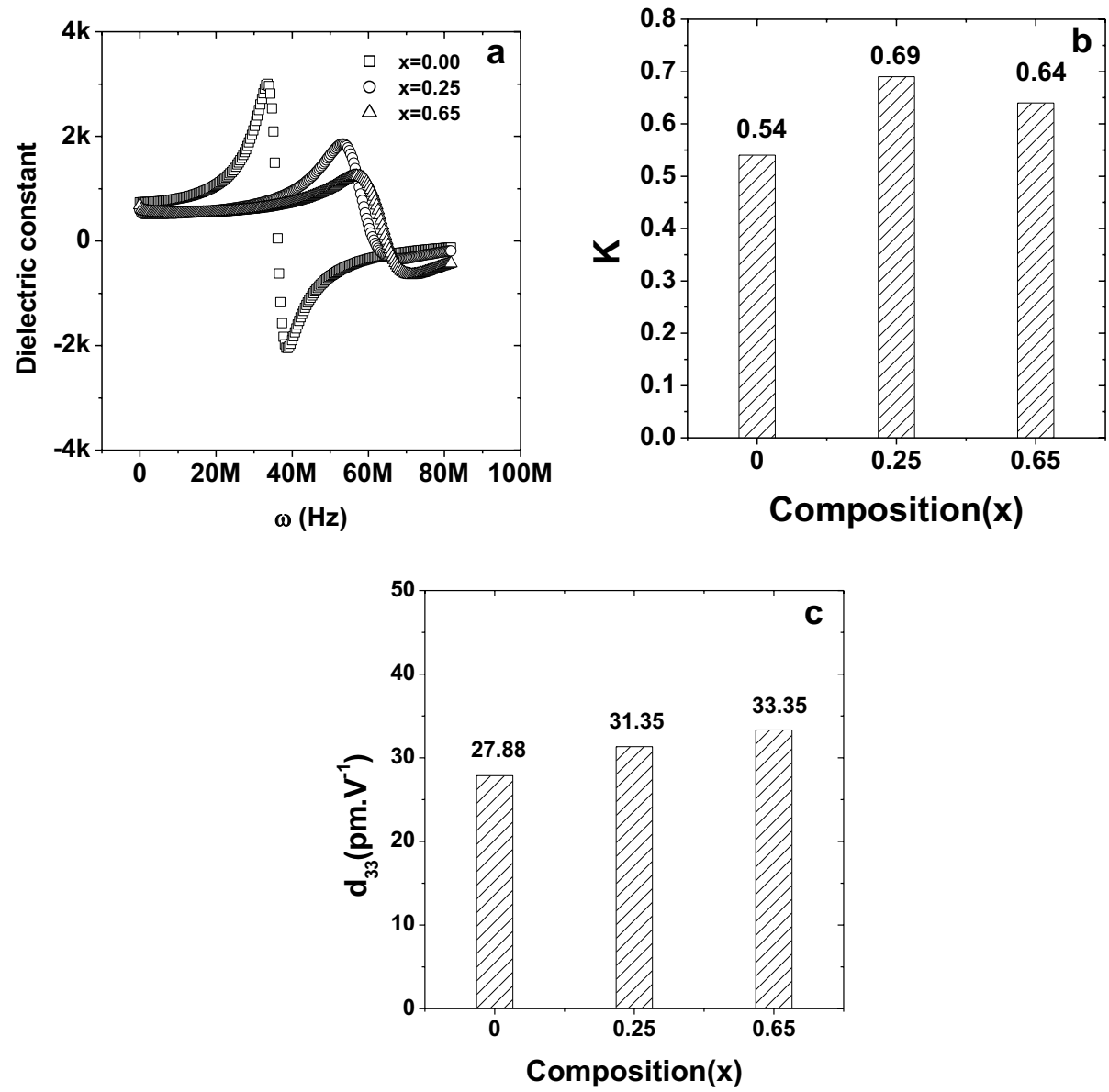

Table 2 Parameters obtained from capacitance resonance and antiresonance data

\begin{tabular}{llll}
\hline Parameters & \multicolumn{2}{l}{ Composition (temperature) } \\
\cline { 2 - 4 } & $x=0.00(T=300 \mathrm{~K})$ & $x=0.25(T=300 \mathrm{~K})$ & $\begin{array}{l}x=0.65 \\
(T=300 \mathrm{~K})\end{array}$ \\
\hline$f_{\mathrm{r}}(\mathrm{Hz})$ & $5.34 \times 10^{6}$ & $6.93 \times 10^{6}$ & $9.06 \times 10^{6}$ \\
$f_{\mathrm{a}}(\mathrm{Hz})$ & $6.18 \times 10^{6}$ & $9.18 \times 10^{6}$ & $11.34 \times 10^{6}$ \\
$K$ & 0.54 & 0.69 & 0.64 \\
$d_{33}\left(\mathrm{pm} \mathrm{V}^{-1}\right)$ & 27.88 & 31.35 & 33.35 \\
\hline
\end{tabular}

result indicates that the oxygen vacancies are desirable to obtain the higher value of piezoelectric charge constant and these materials are best suitable for use in making high-performance transducers and actuators.
Figure 4a shows the modulus resonance and antiresonance data at different temperatures. The different temperatures reported for the various compositions are due to observance of these data at these temperatures. The resonance frequency decreased with the increase in composition $x$. Figure $4 \mathrm{~b}$ and Table 3 show the electromechanical coupling factor for different compositions. The present ceramic material exhibited over $90 \%$ electromechanical coupling conversion. This again may be related to studying these properties with the simultaneous application of high temperature and stress. The stress in the present case is due to studying the electromechanical coupling property in a jig with constant but unknown spring constant. The piezoelectric charge constant for the ceramic with $x=0.00$ is $10.70 \mathrm{~nm} \mathrm{~V}^{-1}$ and increases with the increase in NBT

$d_{33}=\sqrt{\left(C^{\top} * \frac{h}{\frac{\pi * d^{2}}{4}} * \frac{\pi}{2} * \frac{f_{\mathrm{r}}}{f_{\mathrm{a}}} * \tan \left(\frac{\pi}{2} *\left(\frac{f_{\mathrm{a}}-f_{\mathrm{r}}}{f_{\mathrm{a}}}\right)\right) * \frac{\left(\frac{1}{4 * \rho * f_{\mathrm{a}}^{2} * h^{2}}\right)}{1-\left(\frac{\pi}{2} * \frac{f_{\mathrm{r}}}{f_{\mathrm{a}}} * \tan \left(\frac{\pi}{2} *\left(\frac{f_{\mathrm{a}}-f_{\mathrm{r}}}{f_{\mathrm{a}}}\right)\right)\right)}\right)}$ 
Fig. 4 a Modulus versus frequency plots, b electromechanical coupling factor versus composition and c piezoelectric charge constant versus composition
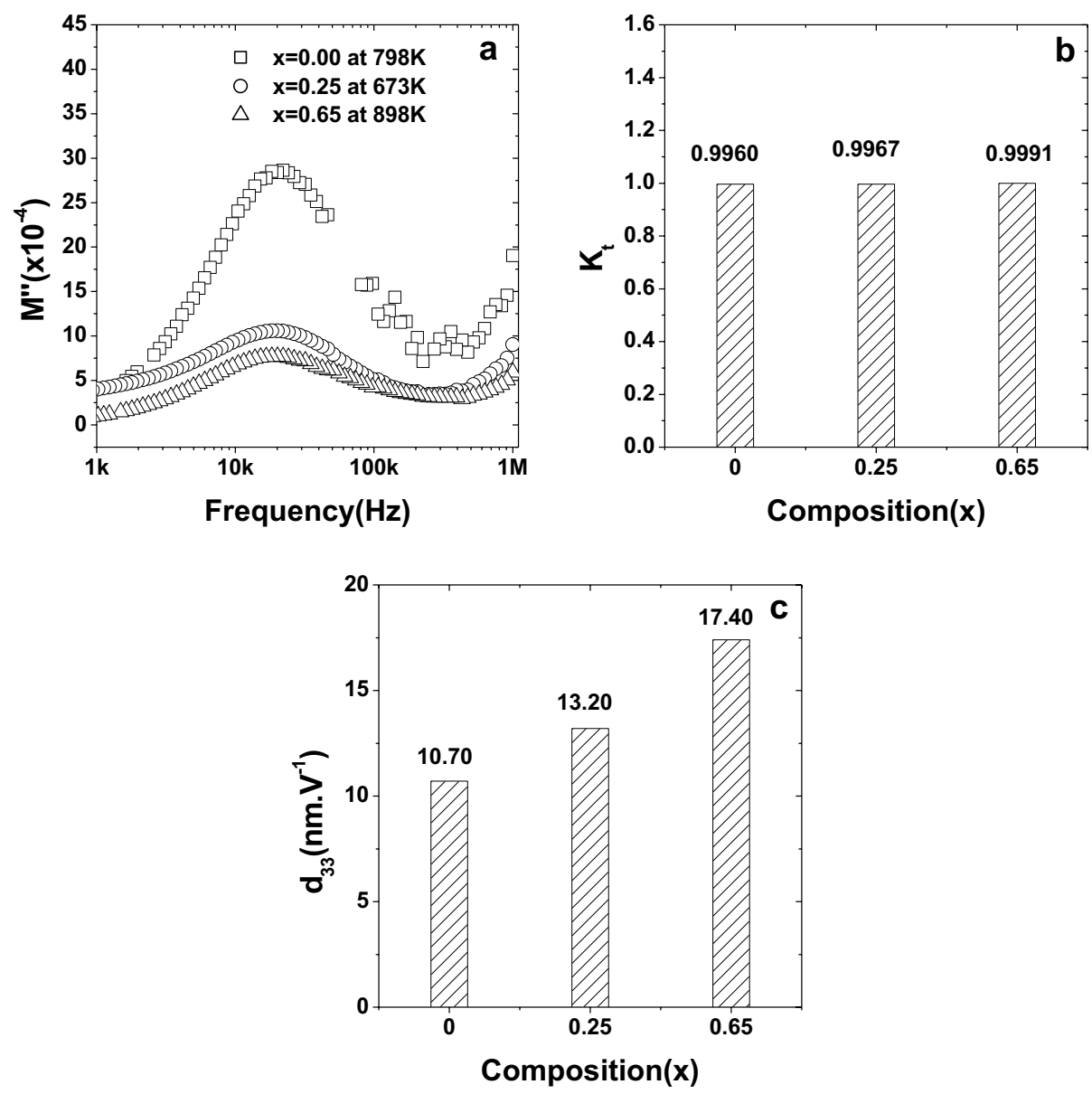

Table 3 Parameters obtained from modulus resonance and antiresonance data

\begin{tabular}{llll}
\hline Parameters & \multicolumn{2}{l}{ Composition (temperature) } \\
\cline { 2 - 4 } & $x=0.00(T=798 \mathrm{~K})$ & $x=0.25(T=673 \mathrm{~K})$ & $\begin{array}{l}x=0.65 \\
(T=898 \mathrm{~K})\end{array}$ \\
\hline$f_{\mathrm{r}}(\mathrm{Hz})$ & 22,050 & 20,090 & 20,090 \\
$f_{\mathrm{a}}(\mathrm{Hz})$ & 225,700 & 225,700 & 432,900 \\
$K$ & 0.9960 & 0.9967 & 0.9991 \\
$d_{33}\left(\mathrm{~nm} \mathrm{~V}^{-1}\right)$ & 10.70 & 13.20 & 17.40 \\
\hline
\end{tabular}

content and attained a value of $17.40 \mathrm{~nm} \mathrm{~V}^{-1}$ for $x=0.65$ ceramic (Fig. 4C). In the present samples, all the samples undergo same constant stress due to jig and hence the increase in piezoelectric charge constant may be attributed to high applied temperature. At these high temperatures, the materials usually become dielectrically and elastically soft in nature and these softer materials produce higher strains with applied electric field. From the above discussion, it can be inferred that the present ceramic materials operating at higher temperature are more dielectrically and elastically softer in nature and hence possess higher value of piezoelectric charge constant. The higher value of piezoelectric charge constant for $x=0.65$ is due to the compositionally induced of piezoelectric charge constant is also due to the fieldinduced strains happening due to the presence of polarized oxygen vacancies at crystal lattice, at interstitial positions and across the grain boundaries. High value of piezoelectric charge constant and electromechanical coupling conversion $\left(d_{33}=2800 \mathrm{pC} / \mathrm{N}\right.$ and $\left.K_{\mathrm{t}}=0.95\right)$ in lead-based single crystals like PMN-0.33PT was reported by Cao [31]. It is to be noted that the unit of $d_{33}$ presented in this paper is $\mathrm{m} \mathrm{V}^{-1}$ and cited from the literature is $\mathrm{C} / \mathrm{N}$. They are different in notation, but it is to be noted here that $1(\mathrm{~m} / \mathrm{V})=1(\mathrm{C} / \mathrm{N})$. In the present ceramics, the higher value of piezoelectric charge constant was observed when compared to that of lead-based single crystal. It is also observed that the values of piezoelectric charge constant at higher-temperature region (798-873 K) are interestingly higher, when compared to at $300 \mathrm{~K}$. This is due to the degree of disorder at $A$ and $B$ sites (due to formation of $\mathrm{AO}, \mathrm{BO}_{6}$ polar clusters) in the ceramic samples. This is also due to softening of crystal softening of lattice with NBT content. The higher value 
lattice at higher temperatures. The higher the temperature is, the more the degree of disorder of polar clusters is, and this leads to larger lattice strains with applied electric field due to more soft lattice. This in turn leads to higher value of piezoelectric charge constant. Similar higher value of piezoelectric charge constant in other ceramic material which is a ternary system based on barium titanate, sodium bismuth titanate and calcium titanate due to temperature and composition-induced strains was reported by us $[32,33]$. This indicates that the above explanation of strains induced by polarized oxygen vacancies formed due to compositional heterogeneity [34] and also due to stress induced by higher temperatures is responsible for the observed enhanced electromechanical conversion and piezoelectric charge constant is proper to say in this way. These results on the present ceramic materials indicate that these materials can be used to design high-temperature and highperformance transducers.

\section{Conclusions}

The present paper describes the dielectric and piezoelectric properties in multi-ferroic ceramics $\left[\mathrm{Ba}\left(\mathrm{Nd}_{0.1} \mathrm{Ti}_{0.8} \mathrm{Nb}_{0.1}\right)\right.$ $\left.\mathrm{O}_{3}\right]_{(1-x)}\left[\mathrm{Na}_{0.5} \mathrm{Bi}_{0.5} \mathrm{TiO}_{3}\right]_{x}$ with NBT content for high-temperature transducer application. Ceramic compositions with $x=0.00,0.25$ and 0.65 exhibited diffused phase transition, and with the increase in NBT content, it increases. The values of electromechanical coupling conversion obtained from the capacitance resonance and anti-resonance data at RT are $54 \%, 69 \%$ and $64 \%$ for $x=0.00,0.25$ and 0.65 ceramic samples, respectively. The piezoelectric charge constant at RT for $x=0.00,0.25$ and 0.65 is $29.88 \mathrm{pm} \mathrm{V}^{-1}$, $31.35 \mathrm{pm} \mathrm{V}^{-1}$ and $33.35 \mathrm{pm} \mathrm{V}^{-1}$, respectively. These ceramic samples operating at higher temperature showed above $90 \%$ electromechanical coupling conversion. The piezoelectric charge constant obtained from modulus resonance and anti-resonance data is $10.70 \mathrm{~nm} \mathrm{~V}^{-1}$ for $x=0.00$ and increases, and with the increase in NBT content, it attained a value of $17.40 \mathrm{~nm} \mathrm{~V}^{-1}$ for $x=0.65$ ceramic. These materials showed three orders of magnitude greater than piezoelectric charge constant studied at higher temperature region (673-898 K) when compared to at RT. This is due to softening of crystal lattice and also due to response of strained polarized oxygen vacancies at these temperatures. These results indicate that the present materials can be used to fabricate high-performance transducers.

\section{Compliance with ethical standards}

Conflict of interest The authors declare that they have no conflict of interest.

Ethical standards The authors followed ethical standards in writing the manuscript.

\section{References}

1. Yang C, Lv P, Song J, Feng C (2016) Ferroelectric and dielectric properties of manganese-doped $\mathrm{Na}_{0.5} \mathrm{Bi}_{0.5} \mathrm{TiO}_{3}$ nanocrystalline thin films prepared by metal organic decomposition: a singlelayer thickness-dependent study. Ceram Int 42(14):15338-15342

2. Chou C-S, Wu C-Y, Yang R-Y, Ho C-Y (2012) Preparation and characterization of the bismuth sodium titanate $\left(\mathrm{Na}_{0.5} \mathrm{Bi}_{0.5} \mathrm{TiO}_{3}\right)$ ceramic doped with ZnO. Adv Powder Technol 23(3):358-365

3. Bhattacharyya R, Omar S (2018) Influence of excess sodium addition on the structural characteristics and electrical conductivity of $\mathrm{Na}_{0.5} \mathrm{Bi}_{0.5} \mathrm{TiO}_{3}$. Solid State lonics 317:115-121

4. Zeb A, ullah Jan S, Bamiduro F, Hall DA, Milne SJ (2018) Temperature-stable dielectric ceramics based on $\mathrm{Na}_{0.5} \mathrm{Bi}_{0.5} \mathrm{TiO}_{3}$. J Eur Ceram Soc 38(4):1548-1555

5. Jankowska-Sumara I, Sitko D, Podgórna M, Pilch M (2017) The electromechanical behavior of europium doped $\mathrm{BaTiO}_{3}$. J Alloys Compd 724:703-710

6. Zhu L-F, Zhang B-P, Yang W-G (2014) Enhancing piezoelectric coefficient $d_{33}$ in LiF-doped $\mathrm{BaTiO}_{3}$ ceramics by optimizing excess Ba content. Mater Res Bull 52:158-161

7. Ali Al, Ahn CW, Kim YS (2013) Enhancement of piezoelectric and ferroelectric properties of $\mathrm{BaTiO}_{3}$ ceramics by aluminum doping. Ceram. Int. 39(6):6623-6629

8. Liu W, Wang J, Ke X, Li S (2017) Large piezoelectric performance of $\mathrm{Sn}$ doped $\mathrm{BaTiO}_{3}$ ceramics deviating from quadruple point. J. Alloys Compd 712:1-6

9. Liu Q, Liu J, Lu D, Zheng W (2018) Colossal dielectric behavior and relaxation in $\mathrm{Nd}$-doped $\mathrm{BaTiO}_{3}$ at low temperature. Ceram Int 44(6):7251-7258

10. Chen W, Zhao X, Sun J, Zhang L, Zhong L (2016) Effect of the Mn doping concentration on the dielectric and ferroelectric properties of different-routes-fabricated $\mathrm{BaTiO}_{3}$-based ceramics. J Alloys Compd 670:48-54

11. Huang $X$, Xing $\mathrm{R}$, Gao $C$, Chen $Z$ (2014) Influence of $\mathrm{CeO}_{2}$ doping amount on property of BCTZ lead-free piezoelectric ceramics sintered at low temperature. J Rare Earth 32(8):733-737

12. Li W, Xu Z, Chu R, Fu P, An P (2012) Effect of Ho doping on piezoelectric properties of BCZT ceramics. Ceram. Int. 38(5):4353-4355

13. Chen X, Wang L, Jia Y, Li Y, Li X, Dong W, Wang B, Wang X (2019) Strongly enhanced ferroelectric performance in Ca-doped barium titanate coatings produced by plasma electrolytic oxidation. Ceram Int 45(10):13024-13029

14. Amini R, Ghazanfari MR, Alizadeh M, Ardakani HA, Ghaffari M (2013) Structural, microstructural and thermal properties of lead-free bismuth-sodium-barium-titanate piezoceramics synthesized by mechanical alloying. Mater Res Bull 48(2):482-486

15. Vijatovic Petrovic MM, Grigalaitis R, Dzunuzovic A, Bobic JD, Stojanovic BD, Šalasevicius R, Banys J (2018) Positive influence of Sb doping on properties of di-phase multiferroics based on barium titanate and nickel ferrite. J Alloys Compd 749:1043-1053 
16. Aravinth K, Anandha Babu G, Ramasamy P (2014) Flux growth and characterization of lead-free Sodium Bismuth TitanateBarium Titanate single crystals. J Cryst Growth 401:787-790

17. Yang F, Wu P, Sinclair DC (2017) Enhanced bulk conductivity of A-site divalent acceptor-doped non-stoichiometric sodium bismuth titanate. Solid State lonics 299:38-45

18. Wang C-M, Wang J-F, Zheng L-M, Zhao M-L, Wang C-L (2010) Enhancement of the piezoelectric properties of sodium lanthanum bismuth titanate $\left(\mathrm{Na}_{0.5} \mathrm{La}_{0.5} \mathrm{Bi}_{4} \mathrm{Ti}_{4} \mathrm{O}_{15}\right)$ through modification with cobalt. Mater Sci Eng B 171(1-3):79-85

19. Mahboob S, Rizwana, Prasad G, Kumar GS (2017) Dielectric, impedance and electromechanical studies on $\left[\mathrm{Ba}\left(\mathrm{Nd}_{0.1} \mathrm{Ti}_{0.8} \mathrm{Nb}_{0.1}\right)\right.$ $\left.\mathrm{O}_{3}\right]_{1-y}\left[\mathrm{Na}_{0.5} \mathrm{Bi}_{0.5} \mathrm{TiO}_{3}\right]_{y}$ relaxor ceramics prepared through conventional and microwave sintering route. Ferroelectrics 506(1):63-75

20. Wu H-Z, Wang C-M, Guo Z-L, Zhao T-L, Wang Y-M (2015) Enhanced piezoelectric properties of Aurivillius-type sodium lanthanum bismuth titanate $\left(\mathrm{Na}_{0.5} \mathrm{La}_{0.5} \mathrm{Bi}_{4} \mathrm{Ti}_{4} \mathrm{O}_{15}\right)$ by B-site manganese modification. Ceram. Int. 41(4):5492-5497

21. Benyoussef $M$, Zannen M, Belhadi J, Manoun B, Dellis J-L, El Marssi M, Lahmar A (2018) Dielectric, ferroelectric, and energy storage properties in dysprosium doped sodium bismuth titanate ceramics. Ceram Int 44(16):19451-19460

22. Syed M, Rizwana X, Prasad G, Kumar GS (2015) Dielectric and piezoelectric properties of microwave sintered $\mathrm{Ba}_{1-x} \mathrm{Re}_{x} \mathrm{TiO}_{3}$ ceramics. Ferroelectrics 486:175-183

23. Swain S, Kar SK, Kumar P (2015) Dielectric, optical, piezoelectric and ferroelectric studies of NBT-BT ceramics near MPB. Ceram Int 41(9, Part A):10710-10717

24. Cernea M, Vasile BS, Capiani C, loncea A, Galassi C (2012) Dielectric and piezoelectric behaviors of NBT-BT ${ }_{0.05}$ processed by sol-gel method. J Eur Ceram Soc 32(1):133-139

25. Kang W, Zheng Z, Li Y, Zhao R (2019) Enhanced dielectric and piezoelectric performance of sol-gel $(1-x) \mathrm{Bi}_{0.5}\left(\mathrm{Na}_{0.78} \mathrm{~K}_{0.22}\right)_{0.5} \mathrm{TiO}_{3}-$ $\mathrm{xBaTiO}_{3}$ derived ceramics. Ceram Int 45(17, Part B):23078-23083
26. Syed M, Dutta AB, Swaminathan G, Prasad G, Kumar GS (2005) Dielectric properties of $\mathrm{BaTiO}_{3}$ based lead free relaxor prepared through conventional and microwave sintering. Ferroelectrics 326:79-84

27. Syed M, Prasad G, Kumar GS (2007) Polarization reversal and electromechanical studies on $\mathrm{Ba}\left(\mathrm{Nd}_{x} \mathrm{Ti}_{1-2 x} \mathrm{Nb}_{x}\right) \mathrm{O}_{3}$ dielectric relaxor ceramics prepared through conventional and microwave sintering route. Mod Phys Letts B 21(13):807-816

28. Bokov AA, Ye ZG (2000) Phenomenological description of dielectric permittivity peak in relaxor ferroelectrics. Solid State Commun 116:105

29. Kroger FA, Vink H (1956) Relations between the concentrations of imperfections in crystalline solids. J Solid State Phys 3:307

30. ANSI/IEEE standards on piezoelectricity (1987) 176:51-54

31. Cao WW (2008) Full-set material properties and domain engineering principles of ferroelectric single crystals. In: Ye ZG (ed) Handbook of advanced dielectric, piezoelectric and ferroelectric materials-synthesis, characterization and applications. Woodhead, Cambridge, pp 235-265

32. Mahboob S, Prasad G, Kumar GS (2015) Characterization of piezoelectric ceramic $\left[\mathrm{Ba}\left(\mathrm{Nd}_{0.1} \mathrm{Ti}_{0.8} \mathrm{Nb}_{0.1}\right) \mathrm{O}_{3}\right]_{0.40}\left[\mathrm{Na}_{0.5} \mathrm{Bi}_{0.5} \mathrm{TiO}_{3}\right]_{0.40}[\mathrm{C}$ $\left.\mathrm{aTiO}_{3}\right]_{0.20}$. Ferroelectrics 482(1):121-128

33. Mahboob S, Prasad G, Kumar GS (2006) Electrical conduction in $\left(\mathrm{Na}_{0.125} \mathrm{Bi}_{0.125} \mathrm{Ba}_{0.65} \mathrm{Ca}_{0.1}\right)\left(\mathrm{Nd}_{0.065} \mathrm{Ti}_{0.87} \mathrm{Nb}_{0.065}\right) \mathrm{O}_{3}$ ceramic. Bull Mater Sci 29(1):35-41

34. Syed M, Prasad G, Kumar GS (2006) Impedance and a.c. conductivity studies on $\mathrm{Ba}\left(\mathrm{Nd}_{0.2} \mathrm{Ti}_{0.6} \mathrm{Nb}_{0.2}\right) \mathrm{O}_{3}$ ceramic prepared through conventional and microwave sintering route. Bull Mater Sci 29(4):347-355

Publisher's Note Springer Nature remains neutral with regard to jurisdictional claims in published maps and institutional affiliations. 